\title{
Высокая подвижность носителей заряда в молекулярных каналах полианилина в нанозазорах между углеродными нанотрубками
}

\author{
(C) А.В. Емельянов ${ }^{1}$, А.В. Ромашкин ${ }^{1}$, К.А. Царик ${ }^{1}$, А.Г. Насибулин ${ }^{2,3,4}$, \\ В.К. Неволин ${ }^{1}$, И.И. Бобринецкий ${ }^{1}$ \\ ${ }^{1}$ Национальный исследовательский университет „МИЭТ“, \\ 124498 Зеленоград, Москва, Россия \\ ${ }^{2}$ Department of Applied Physics, Aalto University School of Science, P.O. Box 15100, \\ Fl-00076 Espoo, Finland \\ ${ }^{3}$ Санкт-Петербургский государственный политехнический университет, \\ 195251 Санкт-Петербург, Россия \\ ${ }^{4}$ Сколковский институт науки и технологий, \\ 143026 Москва, Россия \\ E-mail: emmsowton@gmail.com
}

(Получена 3 августа 2016 г. Принята к печати 11 октября 2016 г.)

\begin{abstract}
Работа посвящена созданию молекулярных полупроводниковых каналов на основе полимерных молекул со сформированными наноразмерными электродами из однослойных углеродных нанотрубок. Предложена воспроизводимая технология формирования наноразмерных зазоров в углеродных нанотрубках с помощью фокусированного ионного пучка $\mathrm{Ga}^{+}$. В сформированные между нанотрубками нанозазоры с шириной до 30 нм под действием электрофореза осаждались молекулы полианилина из раствора в 1-метил-2-пирролидоне. В результате были созданы молекулярные органические транзисторы, в которых исследован полевой эффект и определена подвижность молекулярного канала, равная $0.1 \mathrm{~cm}^{2} / \mathrm{B} \cdot \mathrm{c}$ при отношении токов включения и выключения $5 \cdot 10^{2}$.
\end{abstract}

DOI: 10.21883/FTP.2017.04.44344.8383

\section{1. Введение}

Молекулярная наноэлектроника предполагает создание функциональных элементов на основе манипулирования и управления свойствами одиночных молекул [1]. Одним из базовых элементов молекулярной наноэлектроники является одномолекулярный транзистор, в котором проводимость осуществляется через одиночную органическую молекулу (или малую группу таких молекул) [2-4]. Ключевой проблемой в данных структурах является формирование наноразмерных контактов стока и истока в совокупности с затворным электродом для возможности исследования полевого управления канала. Применение углеродных нанотрубок (УНT/CNT) и методик травления фокусированным ионным пучком (ФИП) позволяет воспроизводимо и технологично формировать нанозазоры необходимых размеров, сопоставимых с длиной одной молекулы [5].

Электроды из углеродных нанотрубок способны достаточно эффективно инжектировать заряд в молекулу, несмотря на то что молекулы могут быть только физически адсорбированы. Значения инжектируемого из УНТ тока больше, чем на порядок, превышают значения тока, инжектируемого из металлических контактов [6]. Проводимость электродов на основе однослойных УНТ может зависеть от потенциала затвора, что затрудняет детектирование изменений в транспорте носителей в одиночных молекулах. Однако в случаях УНТ металлического типа, а также пучков нанотрубок данная зави- симость становится пренебрежимо малой по сравнению с каналом на основе отдельных молекул полианилина (ПАНИ/РАNI) [7] и позволяет измерять свойства самих молекулярных каналов. ПАНИ как основа одномолекулярных полупроводниковых приборов является интересным объектом для исследования ввиду его возможного существования в трех оксидных состояниях, различающихся электронными свойствами.

Исследован эффект поля, оценена подвижность в молекулярном канале, а также определена возможная геометрия перехода УНТ-ПАНИ и влияние структурированности молекулярного канала на свойства транзистора.

\section{2. Методика эксперимента}

\section{1. Материалы и оборудование}

В качестве подложки использовались легированные бором кремниевые пластины (удельное сопротивление $\rho=0.001$ Ом · см) микроэлектронной полировки с термически выращенным слоем оксида кремния толщиной 300 нм. В дальнейшем легированная подложка кремния использовалась в качестве нижнего затвора при проведении измерений вольт-амперных характеристик (BAX) в сформированных структурах.

Электрические характеристики структур исследовались с помощью измерителя параметров полупроводниковых приборов ИППП-1/5 (ОАО „МНИПИ“, Респуб- 
лика Беларусь). Размеры резов, сделанных фокусированным ионным травлением, определялись посредством сканирующей электронной микроскопии (FEI, США).

\section{2. Формирование наноразмерных зазоров в однослойных углеродных нанотрубках}

В работе на подложку диаметром 76 мм осаждались УНТ, выращенные аэрозольным методом химического осаждения из газовой фазы, основанным на термическом разложении паров ферроцена в атмосфере угарного газа [8]. Средняя длина выращенных УНТ составляла $\sim 30$ мкм, диаметр $\sim 2$ нм. Далее методами традиционной фотолитографии к углеродным нанотрубкам форми-

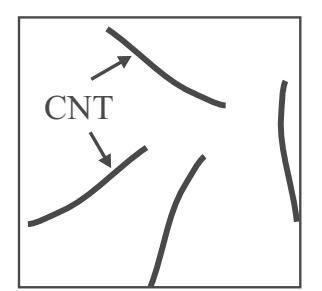

$\mathrm{Au} / \mathrm{Ti}$ deposition
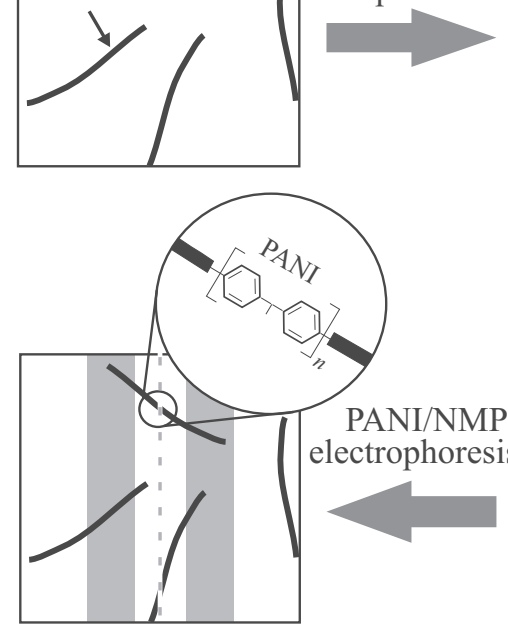

Рис. 1. Схема формирования молекулярных каналов с электродами из УНТ на подложке $\mathrm{Si} / \mathrm{SiO}_{2}$.

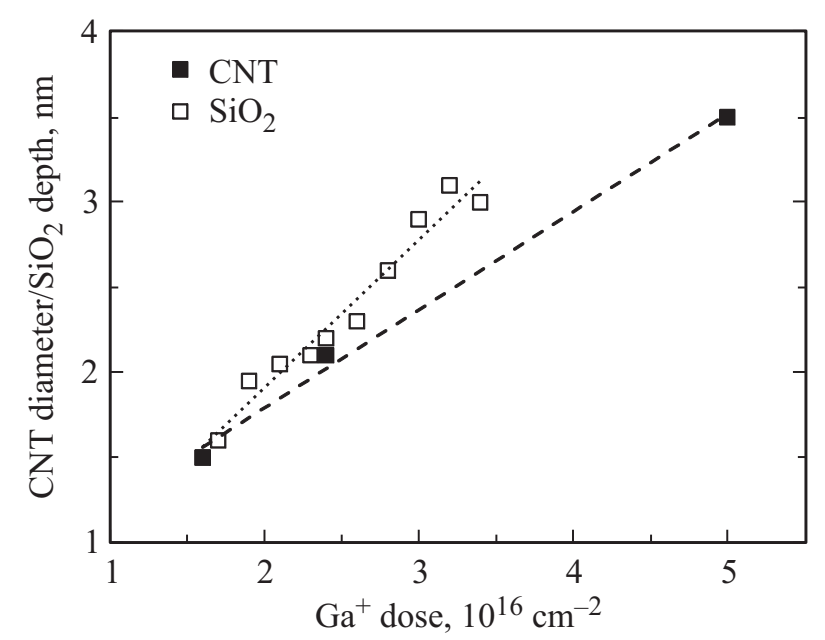

Рис. 2. Глубина травления одиночных УНТ и $\mathrm{SiO}_{2}$ в зависимости от дозы травления ФИП.

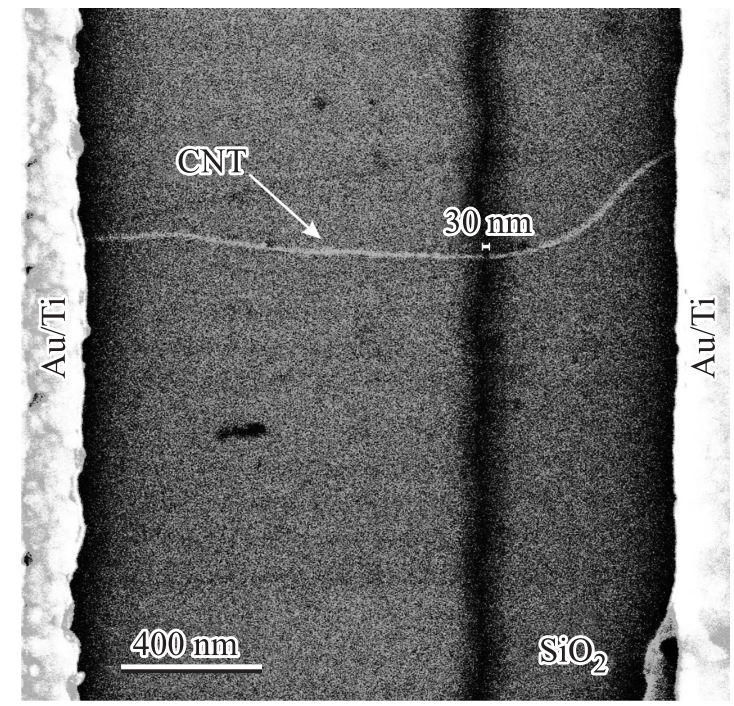

Рис. 3. Изображение, полученное методом сканирующей электронной микроскопии, углеродной нанотрубки между золотыми электродами после фокусированного ионного травления.

ровались электроды Au/Ti (100/10 нм) согласно схеме, приведенной на рис. 1.

Наноразмерные зазоры в УНТ формировались фокусированным ионным пучком $\mathrm{Ga}^{+}$с помощью заранее созданных программных шаблонов для травления. Время воздействия пучка в точке варьировалось в диапазоне от 10 до 800 мкс при токе ФИП 30 пА (соответствующие дозы от $3 \cdot 10^{14}$ до $6 \cdot 10^{16} \mathrm{~cm}^{-2}$, плотность тока пучка ионов $\left.\sim 150 \mathrm{нA} / \mathrm{M \kappa м}^{2}\right)$. В результате была определена минимально необходимая доза для создания разреза в УНТ, равная $1.5 \cdot 10^{16} \mathrm{~cm}^{-2}$, а также диапазон значений доз, приводящих к контролируемому внесению дефектов в УНТ и не приводящих к формированию нанозазора в УНТ (от $3 \cdot 10^{14}$ до $9 \cdot 10^{15} \mathrm{~cm}^{-2}$ ), что коррелирует с результатами других работ [9]. На рис. 2 приведены параметры травления нанотрубок различного диаметpa до полного исчезновения проводимости в канале, сформированном нанотрубкой, в сравнении с глубиной травления диоксида кремния. С помощью фокусированного ионного травления при токе 30 пА были созданы структуры с воспроизводимым размером реза в УНТ от 30 до 50 нм (рис. 3 ).

\section{3. Формирование молекулярных каналов в нанозазоре}

Между сформированными электродами из УНТ были осаждены молекулы полианилина в форме эмеральдинового основания, имеющие средний молекулярный вес $\sim 10000$, т.е. средний линейный размер одной молекулы $\sim 47$ нм. Проводящие свойства полианилина сильно зависят от типа основания и от уровня легирования [10]. Легирование эмеральдинового основания приводит к переходу ПАНИ в эмеральдиновую соль, что увеличи- 
вает его проводимость на 9 порядков. Уровень Ферми УНТ (энергия $\sim 5$ эВ) расположен в запрещенной зоне полимера и очень близок к уровню его высшей занятой молекулярной орбитали (ВЗМО) [11], что должно способствовать высокой инжекции заряда (дырок) из электродов в молекулу. При создании раствора для осаждения полианилина в качестве растворителя был выбран 1-метил-2-пирролидон (НМП/NMP). Раствор, предварительно подвергшийся ультразвуковой обработке и центрифугированию, в виде капли объемом 0.2 мкл с концентрацией молекул 5 мкг/мл наносился на подложку в область контактов. При проведении электрофореза при постоянном напряжении с ограничением по току 50 нА происходило формирование молекулярных транзисторных структур на основе одиночных молекул ПАНИ. Молекулы осаждались преимущественно в зазор между УНТ, так как в нем формировалась большая концентрация линий напряженности электрического поля. Это позволило сделать процесс самоограничивающимся. После формирования структуры напряжение между электродами выключалось, а оставшаяся капля растворителя удалялась.

\section{3. Результаты и их обсуждение}

Были исследованы выходные и передаточные ВАХ (рис. $4, a$ и $b$ соответственно) до и после формирования молекулярных транзисторных структур на основе ПАНИ. Следует отметить, что изначально выбирались структуры с УНТ, обладающие минимальной энергетической щелью (металлического типа) с малым откликом на электрическое поле затвора. Отношение токов включения и выключения $I_{\text {on }} / I_{\text {off }}$ (рис. $4, b$, кривая 1 ) через УНТ до ионного травления составило $\sim 4$, что соответствует слабому полевому эффекту. Влияние контактного барьера мало, о чем свидетельствует линейная характеристика выходной ВАХ. После формирования нанозазора в УНТ ожидаемо произошло полное исчезновение тока (кривая 2 на рис. $4, a$ ) вплоть до 100 пА (предел чувствительности используемой измерительной системы). После осаждения молекул ПАНИ проводимость по отношению к проводимости исходной УНТ упала почти на 2 порядка. В качестве выходной ВАХ мы наблюдаем характерную диодную характеристику, свидетельствующую о присутствии барьера в области контакта молекула/нанотрубка. После осаждения молекул ПАНИ отношение $I_{\text {on }} / I_{\text {off }}$ стало равным $5 \cdot 10^{2}$ (рис. $4, b$, кривая 3). Столь существенную разницу в управлении транзисторной структурой от напряжения $V_{g s}$ до и после реза УНТ можно объяснить наличием управления в молекулярном канале на основе ПАНИ. Если легировать ПАНИ в форме эмеральдинового основания, сделав его проводником, управление станет похожим на изначальное до реза.

В случае молекул ПАНИ при осаждении из раствора между УНТ и молекулой возникают ван-дер-ваальсовы
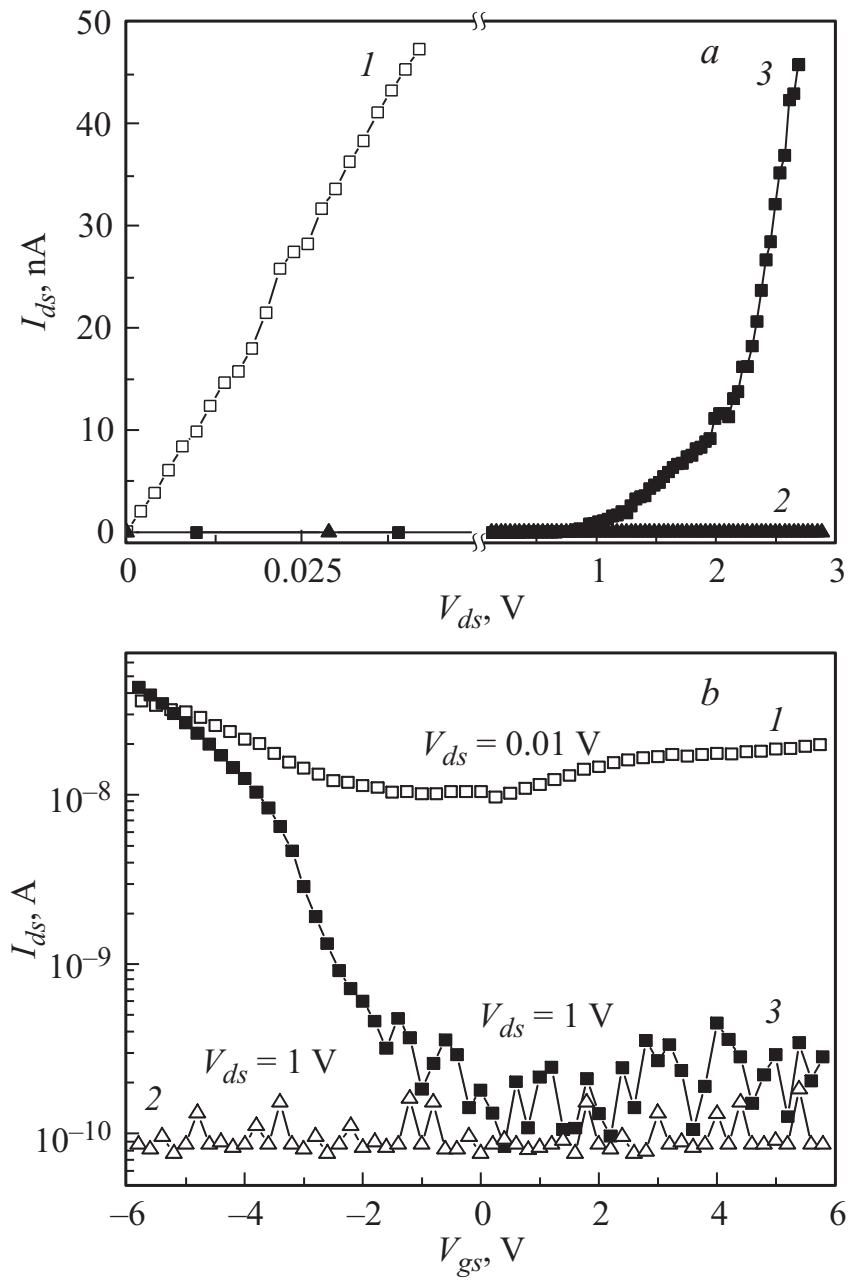

Рис. 4. Выходные $(a)$ и передаточные $(b)$ ВАХ структуры с УНТ: 1 - до, 2 - после формирования нанозазора, 3 - после сформированного в зазоре молекулярного канала. $I_{d s}-$ ток сток-исток; $V_{d s}$ - напряжение сток-исток; $V_{g s}$ - напряжение затвор-исток.

связи, а также нековалентное взаимодействие посредством $\pi$-связей в бензольных кольцах [5]. Таким образом, под действием электрического поля молекула ПАНИ ориентируется и выстраивается преимущественно вдоль зазора в углеродной нанотрубке, формируя нековалентные связи с УНТ (физическая сорбция). Преимуществом нековалентного взаимодействия является тот факт, что молекула необязательно может присоединиться только к краю УНТ, но также и к телу, увеличивая вероятность создания молекулярного канала. Молекулы, соединенные с УНТ посредством $\pi-\pi$-взаимодействия, должны быть менее чувствительны к различным дефектам и хиральности в УНТ. Структурированность зазора в большей степени влияет как на условия контакта УНТ-ПАНИ, так и на крутизну проходной характеристики молекулярного канала ПАНИ. Если ПАНИ после проведения электрофореза не структурировался в зазоре между УНТ, то проводимость отсутствует. 
Для канала на основе сформированного нелегированного молекулярного канала характерно управление p-типа на воздухе. Вклад тела УНТ в управление также есть, но он незначителен, так как изначально УНТ не демонстрировали полное выключение проводимости канала и им можно пренебречь при расчетах подвижности в сформированном молекулярном канале. Таким образом, данную транзисторную структуру можно представить в виде одномерного молекулярного канала и двух точечных контактов с металлическими свойствами.

По формуле для цилиндрического нанопроводника [12] для линейного участка передаточной $\mathrm{BAX}$ (рис. 4, b, кривая 3) можно оценить значение подвижности в канале 30 нм на основе ПАНИ:

$$
\mu=\frac{L \ln (2 h / r)}{2 \pi \varepsilon \varepsilon_{0} V_{d s}} \frac{d I_{d s}}{d V_{g s}},
$$

где $L$ и $r$ - длина и радиус молекулярного канала, $h$ - толщина оксида кремния. Для линейного участка проходной $\mathrm{BAX}$ и для радиуса молекулярного проводника 1 нм подвижность может быть оценена как $\mu \approx 0.1 \mathrm{~cm}^{2} / \mathrm{B} \cdot \mathrm{c}$. Это значение на 2 порядка превышает значение подвижности, полученное ранее для полевого транзистора на основе нановолокна ПАНИ [13], что может быть связано с отсутствием дебаевсокого экранирования в одиночной молекуле ПАНИ, а также с высокой скоростью носителей заряда в отсутствие межмолекулярных барьеров.

Учитывая, что канал сформирован непрерывной молекулой или малой группой молекул, и зная длину одной молекулы, равную $\sim 47$ нм, можно предположить, что в зазоре молекула или группа молекул имеют преимущественно линейную конформацию и транспорт осуществляется через канал длиной 30 нм с радиусом, сопоставимым с радиусом УНТ. Одиночная молекула ПАНИ уже не является по своей природе диэлектриком. Транспорт в ней осуществляется преимущественно по ВЗМО, так как для нее характерно управление $p$-типом проводимости. Дырки довольно интенсивно инжектируются из УНТ: из-за очень большого аспектного отношения диаметра УНТ к ее длине уровень инжекции на острие нанотрубки достаточно высок при напряженностях поля $\sim\left(10^{8}-10^{9}\right) \mathrm{B} / \mathrm{M}$ и, преодолевая барьер, дырки движутся в направлении другого электрода через ПАНИ.

Однако из-за не ковалентной, а только ван-дер-ваальсовой связи между УНТ и ПАНИ на границе между молекулярным каналом и точечным контактом существует энергетический барьер, который может значительно занижать оценку проводимости, а следовательно, и подвижность носителей заряда в самой молекуле.

\section{4. Заключение}

В работе представлено создание одномолекулярного канала на основе молекул ПАНИ и контактов из одиночных УНТ к ним. Показано, что с помощью методик ФИП и электрофореза возможно формирование органического транзистора с длиной канала $\sim 30$ нм, подвижностью $\sim 0.1 \mathrm{~cm}^{2} / \mathrm{B} \cdot \mathrm{c}$ и отношением токов $I_{\text {on }} / I_{\text {off }}>5 \cdot 10^{2}$. На основании полученных значений из передаточной характеристики для молекулярного канала предложена линейная конформация молекул между электродами УНТ, обеспечивающая формирование проводящего канала с эффектом полевого управления.

Исследование выполнено за счет гранта Российского научного фонда (проект № 14-19-01308, МИЭТ).

\section{Список литературы}

[1] B. Capozzi, J. Xia, O. Adak, E.J. Dell, Z.F. Liu, J.C. Taylor, J.B. Neaton, L.M. Campos, L. Venkataraman. Nature Nanotech., 10, 522 (2015).

[2] M.L. Perrin, E. Burzuri, H.S.J. Zant. Chem. Soc. Rev., 44, 902 (2015).

[3] W.-Y. Lo, W. Bi, L. Li, I.H. Jung, L. Yu. Nano Lett., 15 (2), 958 (2015).

[4] N.A. Bruque, M.K. Ashraf, G.J.O. Beran, T.R. Helander, R.K. Lake. Phys. Rev. B, 80 (15), 155455 (2009).

[5] C. Thiele, H. Vieker, A. Beyer, B.S. Flavel, F. Hennrich, D.M. Torres, T.R. Eaton, M. Mayor, M.M. Kappes, A. Gölzhäuser, H.V. Löhneysen, R. Krupke. Appl. Phys. Lett., 104 (10), 103102 (2014).

[6] C.M. Aguirre, C. Ternon, M. Paillet, P. Desjardins, R. Martel. Nano Lett., 9 (4), 1457 (2009).

[7] И.И. Бобринецкий, В.К. Неволин, А.В. Ромашкин. Изв. вузов. Электроника, 2 (94), 27 (2012) [I.I. Bobrinetskii, V.K. Nevolin, A.V. Romashkin. Semiconductors, 46 (13), 1593 (2012)].

[8] A. Moisala, A.G. Nasibulin, D.P. Brown, H. Jiang, L. Khriachtchev, E.I. Kauppinen. Chem. Eng. Sci., 61 (13), 4393 (2006).

[9] K. Maehashi, H. Ozaki, Y. Ohno, K. Inoue, K. Matsumoto, S. Seki, S. Tagawa. Appl. Phys. Lett., 90 (2), 023103 (2007).

[10] K.M. Molapo, P.M. Ndangili, R.F. Ajayi, G. Mbambisa, S.M. Mailu, N. Njomo, M. Masikini, P. Baker, E.I. Iwuoha. Int. J. Electrochem. Sci., 7 (12), 11859 (2012).

[11] O. Kwon, M.L. McKee. J. Phys. Chem. B, 104 (8), 1686 (2000).

[12] Z. Fan, D. Wang, P.C. Chang, W.Y. Tseng, J.G. Lu. Appl. Phys. Lett., 85 (24), 5923 (2004).

[13] D. Chen, S. Lei, Y. Chen. Sensors, 11 (7), 6509 (2011).

Редактор Л.В. Шаронова 


\title{
High carrier mobility in polyaniline molecular channels in nanogaps between carbon nanotubes
}

\author{
A.V. Emelianov ${ }^{1}$, A.V. Romashkin ${ }^{1}$, K.A. Tsarik ${ }^{1}$, \\ A.G. Nasibulin ${ }^{2,3,4}$, V.K. Nevolin ${ }^{1}$, I.I. Bobrinetskiy ${ }^{1}$ \\ ${ }^{1}$ National Research University \\ of Electronic Technology, \\ 124498 Zelenograd, Moscow, Russia \\ 2 Department of Applied Physics, \\ Aalto University School of Science, P.O. Box 15100, \\ FI-00076 Espoo, Finland \\ ${ }^{3}$ St. Petersburg State Polytechnical University, \\ 195251 St. Petersburg, Russia \\ ${ }^{4}$ Skolkovo Institute of Science and Technology, \\ 143026 Moscow, Russia
}

\begin{abstract}
In this paper we report about formation of molecular semiconductor channels based on polymer molecules with nanoscale electrodes made of single-walled carbon nanotubes. The reproducible technology of nanoscale gaps formation in carbon nanotubes using focused $\mathrm{Ga}^{+}$ion beam was suggested. Polyaniline molecules were deposited into nanogaps between nanotubes with a width down to $30 \mathrm{~nm}$ by electrophoresis from 1-methyl-2-pyrrolidone solution. In result, the molecular organic transistors were made. We investigated the field effect, estimated mobility and on/off current ratio of formed single molecular channel, which are $0.1 \mathrm{~cm}^{2} / \mathrm{V} \cdot \mathrm{s}$ and $5 \cdot 10^{2}$, respectively.
\end{abstract}

